\title{
A RADIOGRAPHIC TECHNIQUE FOR THE STUDY OF LUNG PATHOLOGY
}

\author{
BY \\ GEORGE J. CUNNINGHAM AND JOHN W. MILLER \\ From the Department of Pathology, St. Bartholomew's Hospital, London
}

(RECEIVED FOR PUBLICATION SEPTEMBER 19, 1951)

During a radiographic study of lung specimens injected with various radio-opaque materials we were impressed by the amount of detailed structure which could be identified in uninjected areas. It was therefore considered worth while attempting to develop a method for the examination of uninjected lungs by radiography, which, when used in conjunction with recognized histological methods, might provide further information on the structure of lung tissue in health and in disease.

\section{Materials}

To test the method, many lung specimens obtained surgically and post mortem and containing a wide variety of pathological lesions were radiographed. These specimens had been fixed in $10 \%$ formol-saline; in the more recent ones this had been injected into the trachea or main bronchus, but in some older specimens the lung had been simply immersed in the fixative. The preparation of the lung for radiography consisted in slicing it with a sharp knife, great care being taken to ensure that the cut surfaces were as nearly flat as possible. If this was not achieved, it was difficult to fix the specimen securely in the holder. Although these slices could often be cut satisfactorily freehand, we found it desirable to use a simple apparatus (Fig. 1) composed of a wooden trough, the base of which contained a few superimposed plates of glass. The specimen is placed on the glass surface and held there firmly by hand while a section is cut, keeping the knife absolutely flat. As during the sectioning process the knife is resting on the sides of the trough, the thickness of the section will depend on the depth of the trough. The latter can be varied by changing the number of plates of glass placed in its base. The best thickness, though varying according to the pathological lesion in the lung, was usually about 0.5 $\mathrm{cm}$. A few hours before radiography the slices were immersed in methylated spirit, as we preferred to handle the specimens in this rather than in formalin.

\section{Radiographic Technique}

The tube used for the production of $x$ rays was one employed at the Royal College of Surgeons for the study of bone sections (Sissons, 1950). It is similar to tubes used in crystallographic studies and emits rays at a voltage of 5 to 35 kilovolts. These rays consist of a narrow beam produced by the linear focus technique (Eastman Kodak publication, 1943), the size of the focal spot being $0.3 \mathrm{~mm}$. In our initial trials a large number of radiographs was taken at varying voltage and amperage. For reasons which will be discussed later when considering the distance between film and $x$-ray source, most of our recent and better results were obtained with voltages from 20 to 35 kilovolts and with currents of from 10 to 25 milliamperes. As the $x$-ray beam emitted by the apparatus was horizontal, some form of holder for the specimen was necessary. In the earlier trials small pieces of lung were used and these could be made to adhere to the film container by means of their moisture, this method proving satisfactory, 


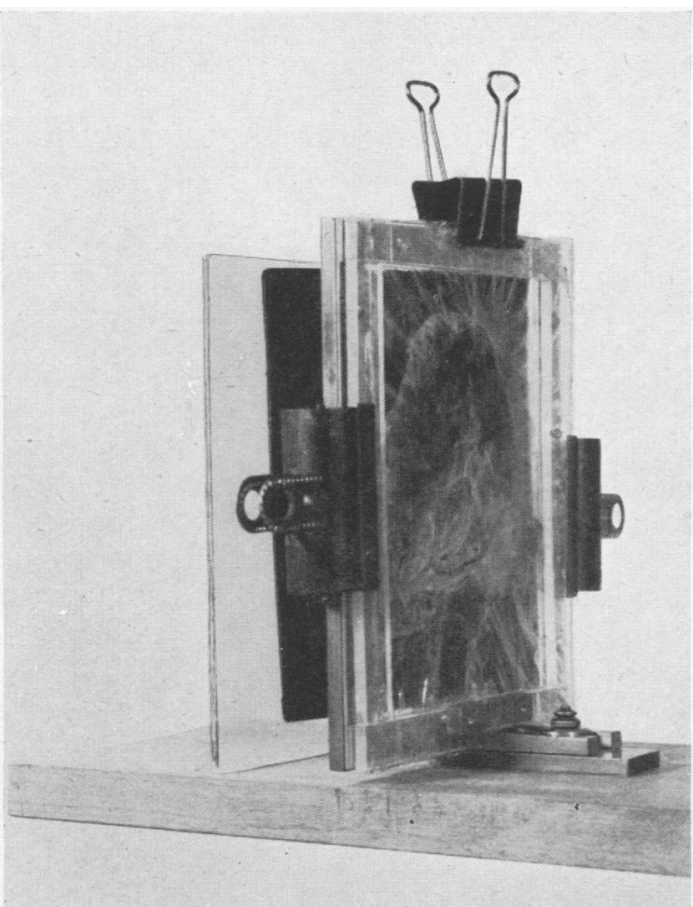

FIG. 2.-The holder partly'assembled with specimen in position.

especially if the exposure time was short. When larger portions of tissue were used and the exposure times were increased, any slight movement of the specimen-spoiled our results and forced us to employ a holder. We were fortunate in having the assistance of Mr. S. P. Steward, of the Physiological Department, Royal College of Surgeons, and he was responsible for the holder illustrated here (Figs. 2 and 3). It has proved to be very satisfactory and our results greatly improved with its use. It is composed of two frames, one made of metal and the other of perspex. These two frames can be approximated one to the other once the specimen has been placed in position, and maintained there by means of a screw-clamp. It was thought that the perspex frame might be too fragile for the work, but it was carefully handled and was in good condition after two months' continuous use. In fact its elasticity seemed to be an advantage, as it held the specimen firmly in position without compressing it too strongly. Each of these frames was covered by a single layer of cellulose acetate sheeting* $3 / 1000$ in. thick. The sheeting was stretched tightly over the frames and fixed in position by means of cellophane tape. The specimen was thus held between these two layers of sheeting. Before placing the slice of lung between the frames it was lightly blotted to absorb any excess of methylated spirit. Although the cellulose acetate sheeting when moistened by the spirit buckled to some extent, there was little distortion left on drying and we did not have to change

\footnotetext{
* Obtainable from Messrs. F. G. Kettle, 23. New Oxford Street,
} London, W.C.1.

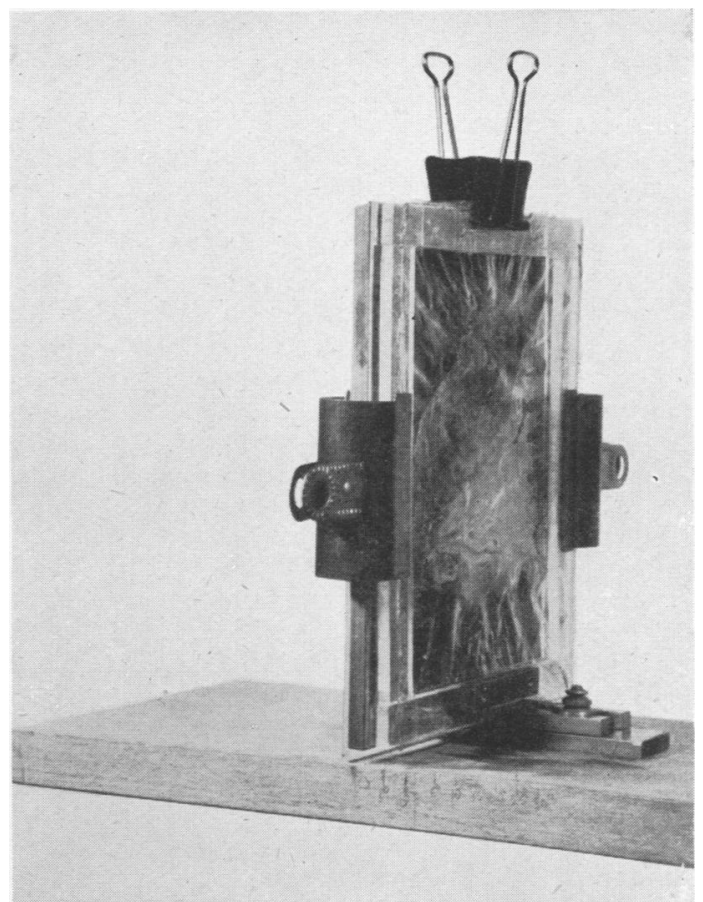

Fig. 3.-The holder fully assembled and ready for radiography.

the original sheets during a trial period of two months. If such a change should become necessary it can be performed quite easily.

As this kind of radiography is usually performed in the light, many workers have employed a light-tight container in which both specimen and film are placed, the unit being assembled in a dark room. We considered that it would be simpler to make a light-tight holder for the film only, as it would then be possible to arrange the specimen in the holder in daylight. For this purpose, after trying various materials, envelopes were made from the type of black paper that is ordinarily used for packing $x$-ray films, but after having used it for some time we were surprised to discover that other workers had condemned its use. They found that the texture of the paper was visible on the radiograph and thus interfered with the image. These workers were using voltages of 2 to $\mathbf{8}$ kilovolts, and this almost certainly accounts for their findings, as we never encountered any such difficulties. The film container was strengthened by a piece of cardboard identical in size with the film and placed inside the envelope.

When loading the container care had to be taken to place the film in front of the sheet of cardboard and to avoid tearing the black paper at the top corners of the envelope when inserting the film. The loaded film container is placed in the metal frame, thus bringing it into direct contact with the layer of sheeting behind the specimen. The latter is, therefore, only separated from the film emulsion by two thin layers of material, namely the black paper and one layer of the cellulose acetate 
sheeting. Any space behind the film container in the metal frame is filled in with a suitable number of sheets of cardboard (in our case three), and the back of the frame covered with a sheet of perspex. All the constituents of the holder were then held firmly together by means of three large metal clips placed as indicated in Fig. 3.

The distance of the film from the focal spot has usually been about $12 \mathrm{in}$. $(30.5 \mathrm{~cm}$.) according to earlier workers, though Barclay (1947) used 8 in. $(20.3 \mathrm{~cm}$.). We began by employing a distance of 20 to 24 in. (50 to $60 \mathrm{~cm}$.), but soon found that the cone of $x$ rays at that distance would not be sufficiently large to enable whole lobes of lung to be radiographed. We aimed at obtaining a cone which would easily cover an area of $41 \times 6 \frac{8}{4}$ in. $(10.8 \times 17.1 \mathrm{~cm}$. $)$, and this could be achieved at a distance of not less than $33 \mathrm{in} .(83.8 \mathrm{~cm}$.), though the distance we actually used was $36 \mathrm{in}$. $(91.4 \mathrm{~cm}$.). This increase necessitated a considerably longer exposure and required a rise in the kilovoltage from between 15 and 20 to between 30 and 35 . These radiographs appeared to us better defined than our previous ones. Franke's formula (Bohatyrtschuk, 1944) indicates the factors which cause blurring of the image:

$$
\mathrm{W}=\frac{\mathrm{bd}}{\mathrm{F}-\mathrm{b}}
$$

where

$$
\begin{aligned}
& W=\text { the blurring, } b=\text { the distance of object } \\
& \text { from film, } d=\text { the size of the focal spot, and } \\
& F=\text { the target-film distance }
\end{aligned}
$$

Thus, with an object almost in contact with the film, an increased distance from the tube is an advantage provided that the resulting increase in exposure is not too great. Many of our later and better radiographs, including those illustrated in this article, were taken at 35 kilovolts and 25 milliamperes. We found that under these conditions a slice of lung $0.5 \mathrm{~cm}$. thick required an exposure of three to four minutes.

After some initial failures with ordinary types of orthochromatic photographic emulsions we eventually came to use either Ilford process or line films. At the time of writing we favour the latter, though they are a trifle slower and thus require a slightly longer exposure. We used Johnson's fine-grain contrast developer, and were able to obtain magnifications of 25 diameters without loss of detail. We have, unfortunately, not been able so far to try the special fine-grain emulsions referred to by Barclay and his colleagues in their renal studies (Trueta, Barclay, Daniel, Franklin, and Prichard, 1947).

\section{Historical}

Although hard $x$ rays are used so much in medicine, dentistry, and metallurgy, the uses of softer or Grenz rays are not so well recognized. Of recent years medical workers have had their attention drawn to them by the researches of Barclay and his colleagues $(1947,1951)$ on microarteriography of kidneys injected with radio-opaque materials.
The earliest application of radiography to the $\stackrel{\overrightarrow{\bar{\omega}}}{\vec{T}}$ study of the structure of soft tissues was made by Goby (1913), who studied diatoms and foraminifera. $\frac{\sigma}{\bar{\omega}}$ The results he obtained were remarkably good when $\frac{\rho}{\Phi}$ one considers the limited facilities at his disposal. $\stackrel{\mathbb{Q}}{\varrho}$ They were not entirely satisfactory, as he employed $x$ rays that were too hard, and the coarseness of his $\overrightarrow{0}$ photographic emulsions prevented him from obtaining enlargements of more than 17 diameters. Since $\vec{\omega}$ then similar studies have been made with considerable success by other workers (Fricke, 1932; Sher- $x$ wood, 1934, 1936, 1937). Seeds as well as insects $v$ have been studied and the distribution of radio-? opaque organic spray materials on foliage deter- $\checkmark \checkmark$ mined (Eastman Kodak, 1943). In 1930 Dauvillier 을 carried out the first successful radiograph on $\mathrm{a}_{-}$ histological section of plant tissue. He employed a $\subsetneq$ very thin section, used a special fine-grain emulsion $\frac{\varsigma}{(\Phi}$ photographic plate, and claimed to have been able $\overrightarrow{\vec{c}}$ to magnify his negative up to 600 diameters. This of work was followed by that of Lamarque (1938), who obtained beautiful radiographs of skin sections and called the technique histo-radiography. His positive prints, suitably magnified, compared very favourably with photomicrographs taken from the

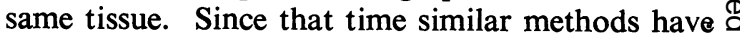
been used for a remarkable number of different $\overline{\bar{O}}$ purposes. Forgeries in postage stamps can frequently 3 be detected (Cheavin, 1948). Seemann (1943) in an excellent article cites such uses as the detection of grubs and death-watch beetles in wood, the distinction between natural and cultured pearls, and the extreme ease with which natural and artificial $\stackrel{\infty}{x}$ leather can be distinguished radiographically. He also mentions its use in the textile industry, about which Sherwood (1936) has also written. Grenz radiography has been in use in this industry for at least 15 years, as excellent pictures showing the weave of the cloth can be obtained.

\section{Discussion}

Of recent years, micro-radiography has become $N$ increasingly employed, chiefly as a result of the researches of Bohatyrtschuk (1944), Barclay (1947, 1949, 1951), and Trueta et al. (1947). With the exception of Sissons (1950), who was studying bone, all the other workers injected the tissues with radioopaque materials. Several organs have been studied, including the kidney, stomach, spleen, liver, and diaphragm (Bohatyrtschuk, 1944; Barclay, 1947, 1949, 1951 ; Woolf, 1950; Tirman and others, 1951). Barclay (1951) attempted micro-arteriography of the lung, but was not satisfied with the definition he obtained; Tirman and others (1951) in their paper published magnified radiographs of 
injected lung specimens, but the details are not easily recognizable. While our method closely resembled that of Barclay (1947) and of Sissons (1950), a voltage slightly higher than that of Grenz rays was employed. Most of the workers quoted took radiographs at a voltage below 20 kilovolts. We took our radiographs at a distance of 36 in. $(91.4 \mathrm{~cm}$.) to fill a half-plate field, and used a higher voltage to keep the exposure time within reasonable limits. Had we found it necessary to use voltages of 5 to 10 kilovolts, an exposure of one to two hours would have been necessary at that distance. This we felt undesirable, as it would greatly limit our number of exposures. A more serious objection was the fact that the specimen might shrink by drying and therefore the lung slice in the holder would be more likely to move.

In examining a number of specimens we were impressed by the information obtained of the general distribution of the disease process. It was obvious that a precise idea of the extent of certain lung lesions could be obtained by serially slicing the lung and making radiographs of each slice. By this procedure the task of the histologist in selecting suitable areas for section would be greatly simplified.
FIG. 4-A photograph. a radiograph, and a histological section of the same slice of tissue from a case of carcinoma of the lung. The pneumonic areas can be seen extending outwards to the pleural surface. (About twothirds of actual size.)

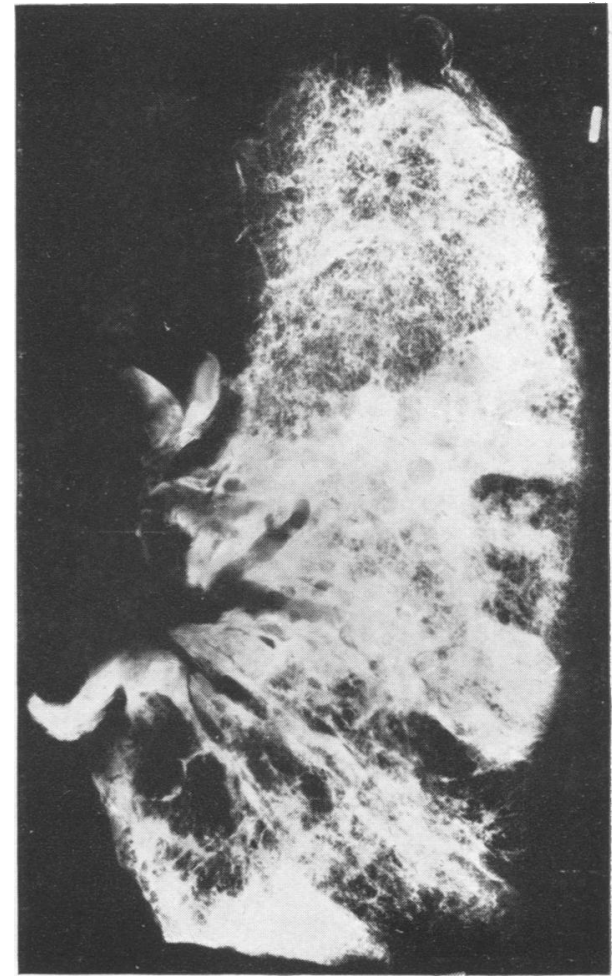

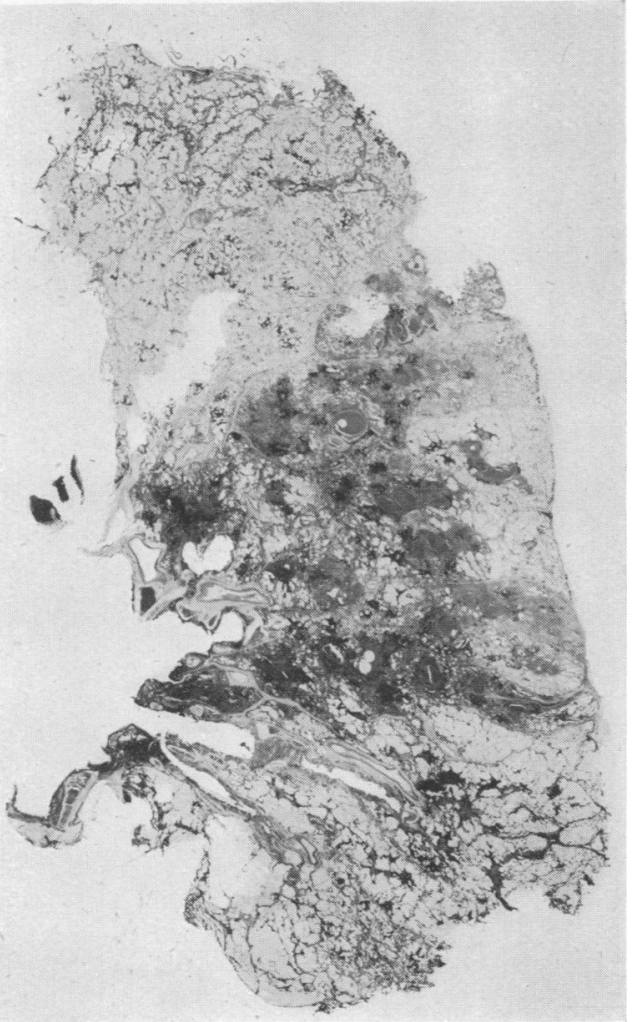




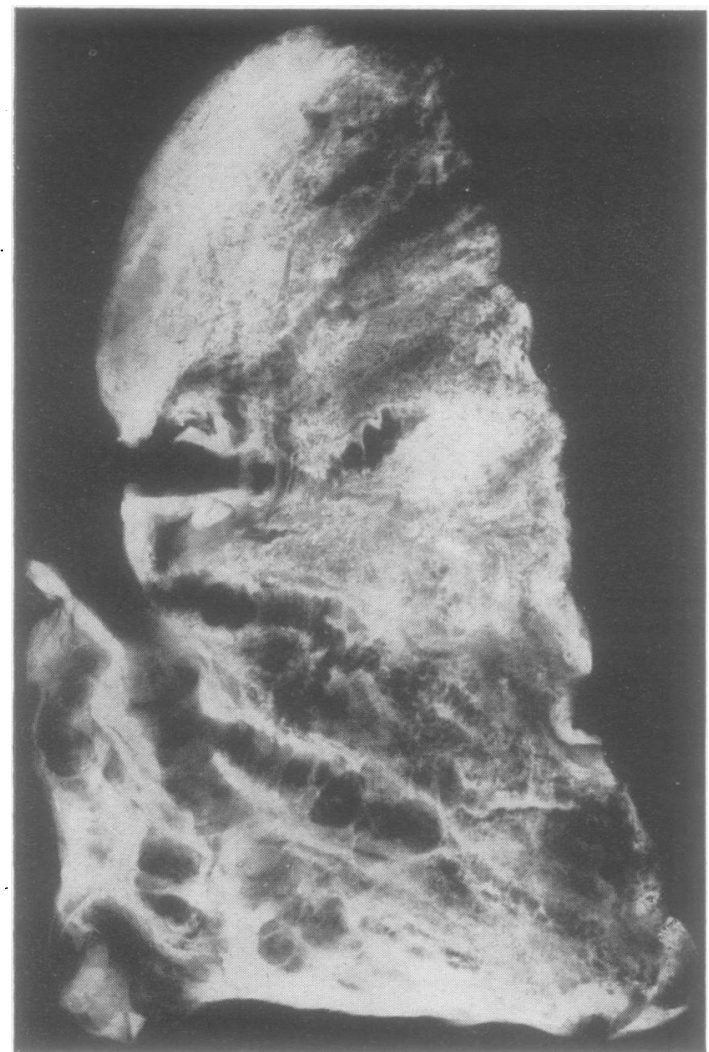

Fig. 5.-A similar illustration to Fig. 4 of a portion of bronchiectatic lung. Note the tuberculous focus in the upper part of the lobe. Actual size.

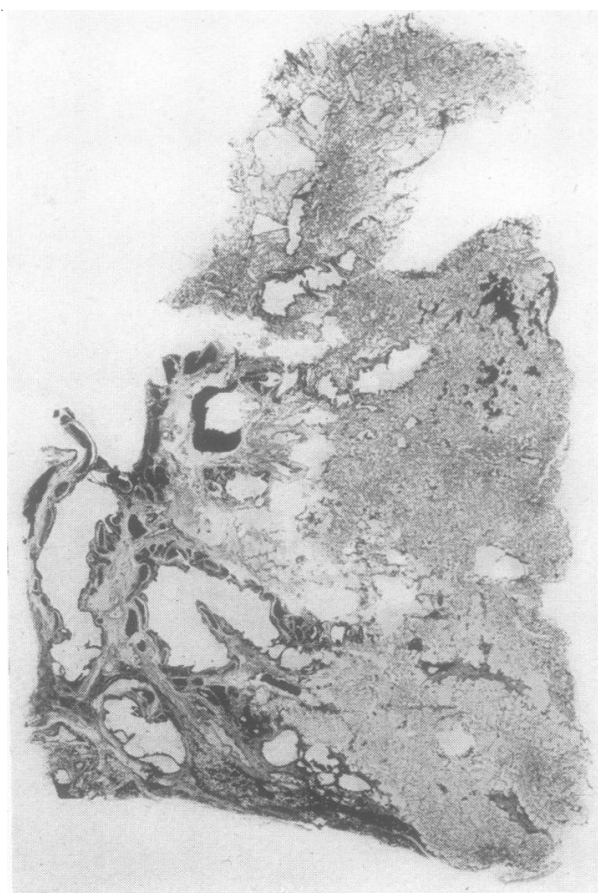

A great additional advantage was that the material could be sectioned histologically and yet a permanent record kept of its macroscopic appearances for comparison.

In Fig. 4 a specimen from a case of bronchial carcinoma is illustrated by a photograph and a radiograph of the specimen, together with a photograph of the histological section. The extent of the lesion can be well seen in the radiograph, and histological examination proved that the shadows extending out to the pleural surface were pneumonic, following bronchial obstruction by the neoplasm. In Fig. 5 a specimen of bronchiectasis showing basal distribution is similarly illustrated. The small tuberculous focus, unsuspected before operation, can be seen in all three pictures.

Lamarque (1938) laid considerable emphasis on the varying radio-densities of tissue and hoped that histo-radiography with Grenz rays might prove a

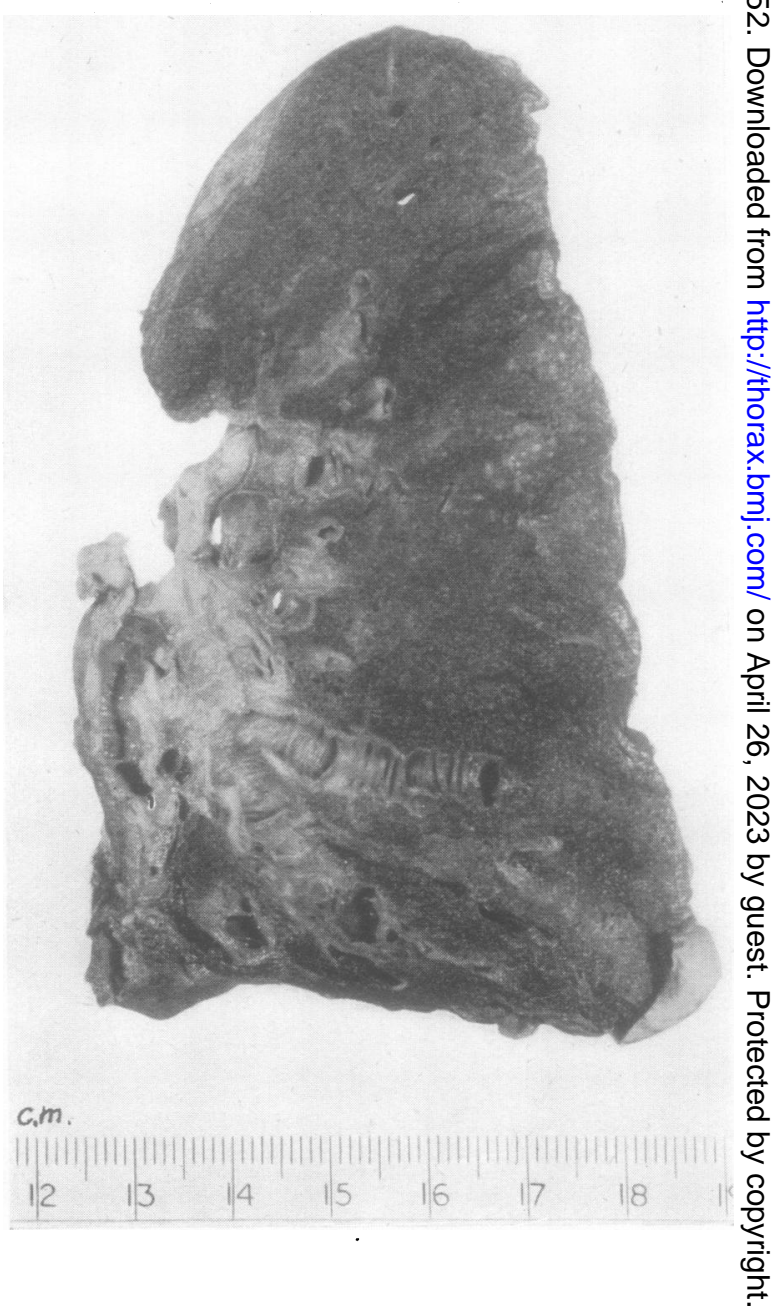




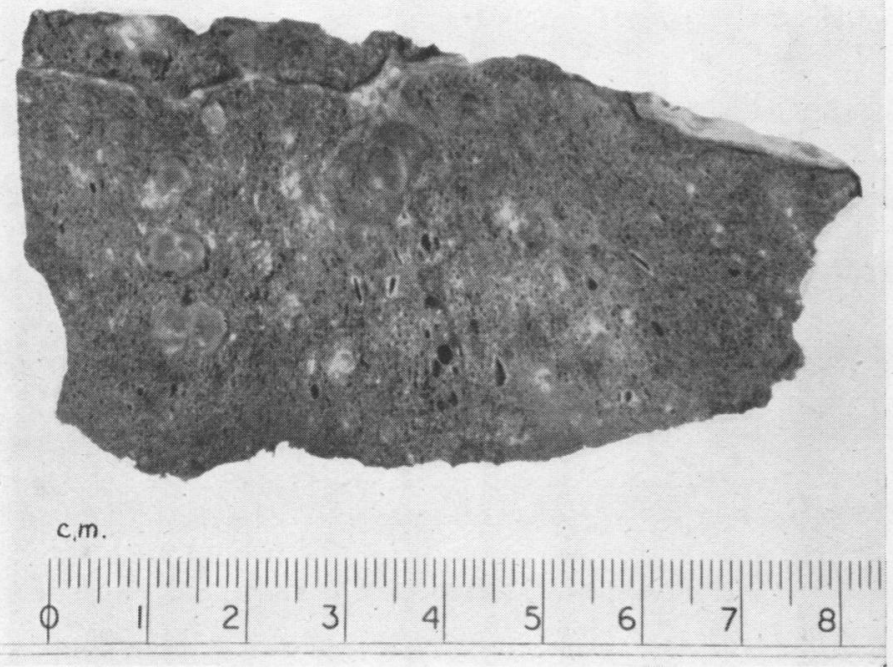

FIG. 6.-Illustration of a portion of silicotic lung, showing nodules. Actual size.

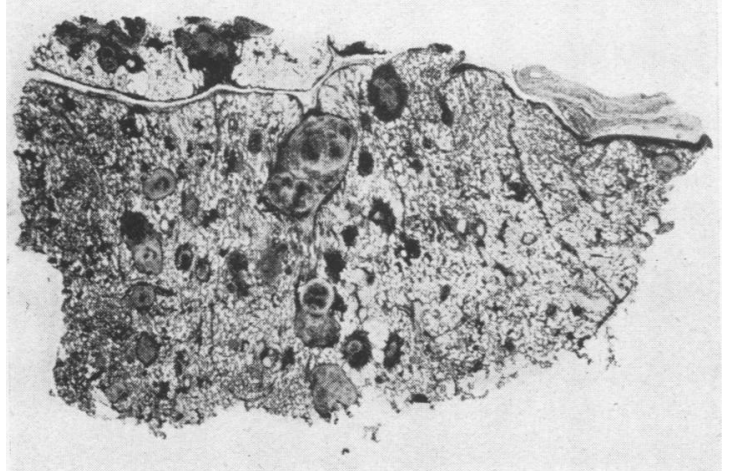

method of analysis for different kinds of tissue. In studying the relative opacities to $x$ rays of a number of tissues he found that connective tissue fibrils were relatively opaque compared with ordinary cellular elements. This point is well illustrated by the portion of silicotic lung (Fig. 6). Here the detail of the silicotic nodule is so clear that the whorled arrangement so characteristic of collagenous tissue can be seen if a small hand-lens is used in examining the radiograph. Again, in Fig. 7 the radiograph of the portion of emphysematous lung shows the abnormal connective tissue framework very clearly, and the advantages compared with the accompanying photographs of the specimen and histological section are easily apparent. The lung tissue would thus appear ideal for this method of study, as its basic structure of radio-opaque connective tissue contrasts strongly with the alveolar spaces. Examination of the radiographs shown in this paper emphasizes how advisable it is to inflate the

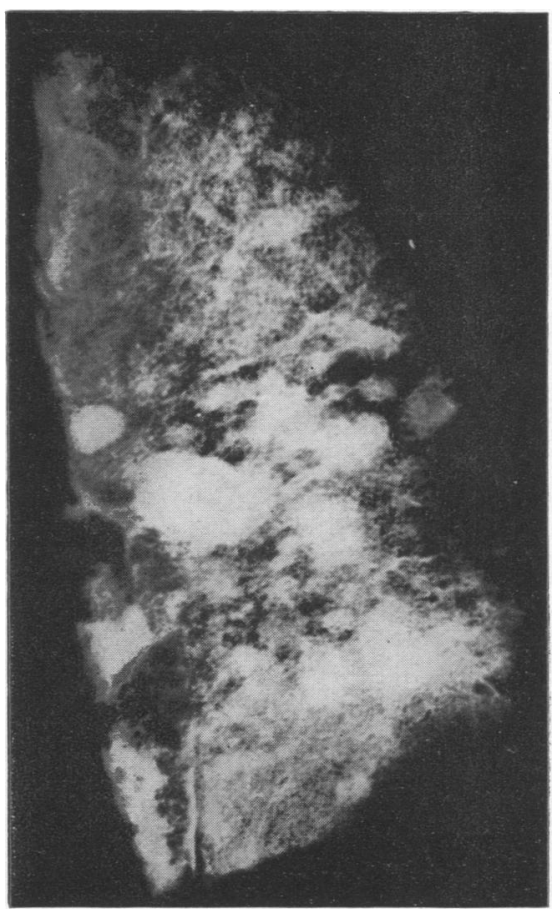

lung at the time of fixation. In Fig. 5 the lung tissue has not been satisfactorily inflated, and this defect is most obvious in the apex of the bronchiectatic lobe. While it is likely that Lamarque's hope of a radiographic method for analysing tissue composition is demanding too much of the method, we have obtained some interesting results in the radioopacity of a few pathological conditions. A specimen of lung from a coal-miner, kindly given to us by Professor Gough, of Cardiff, showed the presence of a large amount of carbon. We radiographed this specimen in an attempt to illustrate the precise distribution of the pigment and found that the radio-opacity was much less than we had expected. Hence radiography in this type of lung might provide information of any modification in structure of the connective tissue framework of the lung in coal-miners' pneumoconiosis. This might be valuable, since the histological structure may be completely obscured by dense areas of carbon pigmentation. We have been informed that such a method has been used for revealing the pattern of a postage stamp which had been obscured by heavy postmarks of carbon-containing ink. Lamarque cut his sections very thin $(4-10 \mu)$, as he was anxious to avoid a large number of superimposed shadows which he would be unable to analyse. We considered that thick slices were essential for our purpose, and our aim was therefore in direct contrast to that 


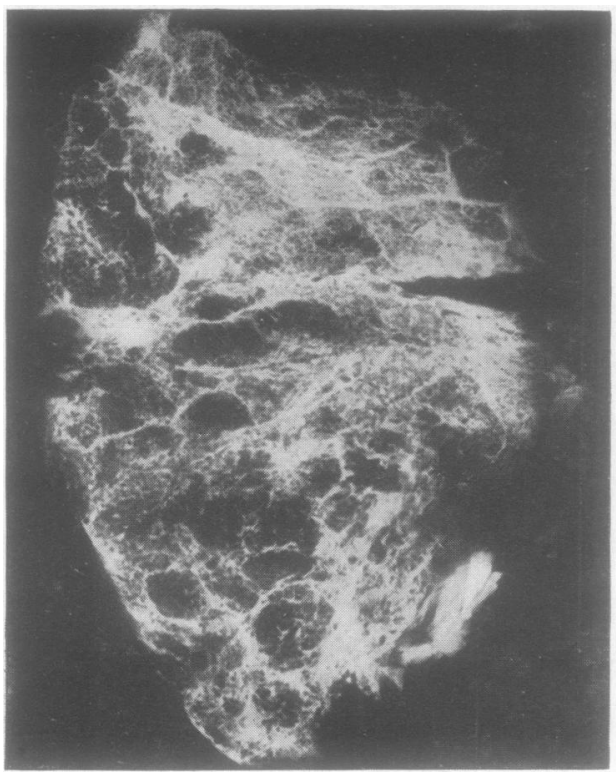

of Lamarque. Like many histologists, we have always considered that thin sections are most unsatisfactory for giving any real idea of such an essentially three-dimensional structure as the lung lobule.

The combined technique which we have illustrated has been invaluable to use in providing a more complete idea of certain lung lesions. Apart from this the radiographic definition is sufficiently good to enable the negatives to be easily examined by magnification on a dissecting microscope. This fact seemed to us to extend the possibilities of the method to the examination of the more intimate pulmonary histology. It was realized, however, that radiographs of thick slices should be interpreted with caution owing to the complexity of the picture and the possibility of artefacts produced by the superimposition of shadows. We considered that the best way to avoid these difficulties was to obtain stereoscopic radiographs, rotating the specimen and taking two pictures, each at an angle of $5^{\circ}$ from the mid-line position. We have now modified a Wheatstone stereoscope to our requirements and have obtained results which appear to be most promising. Stereoscopic radiographs can be considerably enlarged, and when viewed in the stereoscope they show the intimate lung structure in a most striking way. These stereoscopic views are similar to those obtained by examining a slice of lung under the dissecting microscope. They show, however, a greater depth of tissue, and have the great advantage of providing a permanent

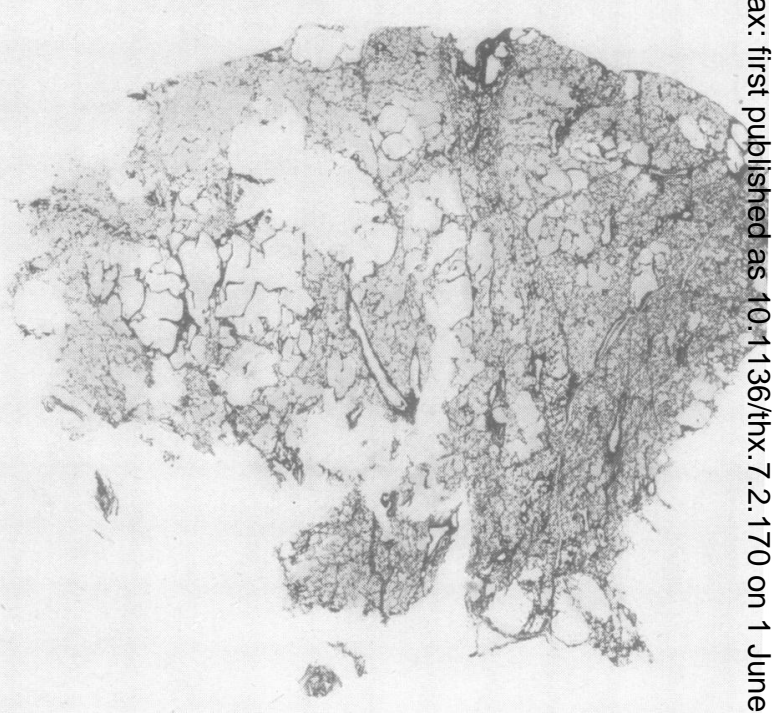

FIG. 7.-Portion of an emphysematous ung, showing a number of bufㅛ

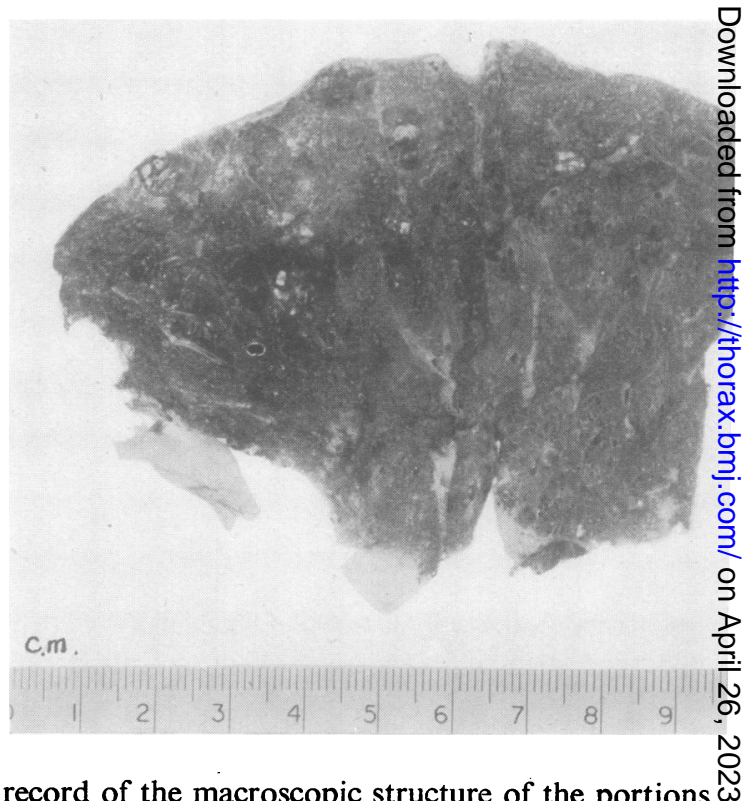

record of the macroscopic structure of the portions $\mathrm{\omega}$ of tissue to be sectioned. An added advantage is that, if during histological examination any interest- 0 ing feature be found, reference to the deeper struc- $\mathbb{\Phi}$ tures in the stereoscopic radiographs may show + whether any useful purpose would be served by ${ }^{T}$ cutting further sections from the block. Comparison $\frac{\vec{\Phi}}{\mathbb{D}}$ between radiograph and histological section is $\stackrel{\odot}{\mathscr{P}}$ greatly facilitated by their similarity in size (the $\stackrel{\unrhd}{\varrho}$ section being only slightly smaller owing to shrinkage $\bar{\sigma}$ as the radiograph is really a contact negative. This enables individual lung structures to be응 
measured by a simple scale during stereoscopic examination.

Our results will give some idea of the scope and value of this method, which we believe is ideal for record purposes and for providing information of a more complete character in lung specimens. We should at the same time like to emphasize that we regard the detailed interpretation of these radiographs as an exceedingly complex matter, and one in which much practice and further research will be required before conclusions are too readily drawn. At the moment we consider that its place is to assist the pathologist in obtaining a threedimensional view of the lesion, and that its function is therefore ancillary to the histological method.

\section{SUMMARY}

A technique for examining slices of lung by soft $x$ rays is described. By radiography of serial slices and subsequent histological examination an accurate picture of the whole lesion may be obtained.

The radiographs can be greatly magnified and thus the finer details of the lung examined.

Stereoscopic radiography in conjunction with orthodox histological methods is likely to prove of great value in obtaining a better conception of the lung lobule in health and disease.
The radiographs provide a permanent record of the macroscopic appearances and are more informative than ordinary photographs.

We should like to express our gratitude to Professor J. W. S. Blacklock for much encouragement; to Professor G. Hadfield for allowing us the use of the $x$-ray apparatus and for helpful advice; to Professor D. Slome for encouragement and many valuable suggestions; to Mr. Norman K. Harrison for the photography; to Dr. G. S. Sansom for the photomicrography.

\section{REFERENCES}

Barclay A E (1947), Brit. J. Radiol., 20, 394.

(1999). Amer. J. Roentgenol., 62, 119

(1949). Amer. J. Roentgenol.,62, Micro-arteriography and Other Radiological Techniques Employed in Biological Research. Oxford.

Bohatyrtschuk, F. (1944). Acta radiol., Stockh., 25, 351.

Cheavin, W. H. S. (1948). Research, 1, 208.

Dauvillier A. (1930). C.R. Acad. Sci., Paris, 190, 1287.

Eastman Kodak Company X-Ray Division (1943). Radiography of Materials. Rochester, N.Y.

Fricke, H. (1932). Radiogr. and clin. Photogr., 8, No. 5, p. 12.

Goby, P. (1913). C.R. Acad. Sci., Paris, 156, 686.

Lamarque, P. (1938). Brit. J. Radiol., 11, 425.

Seemann, H. E. (1943). In Symposium on Radiography, 1936 and 1942, p. 29. American Society for Testing Materials, Philadelphia, Pennsylvania.

Sherwood, H. F. (1934). Radiogr. and (lin. Photogr., 10, No. 4, p. 10. (1936). J. Text. Inst., Manchr. (Trans.), 27, T162.

(1937). J. biol. photgr. Ass., 5, 138

Sissons, H. A. (1950). Brit. J. Radiol., 23,2

Tirman, W. S., Caylor, C. E., Banker, H. W., and Caylor, T. E. (1951). Radiology, 57, 70.

Trueta, J., Barclay, A. E., Daniel, P. M., Franklin, K. J., and Prichard, M. M. L. (1947). Studies of the Renal Circulation. Oxford.

Woolf, A. L. (1950). Brit. J. Radiol., $23,8$. 